\title{
Morphological and Pathogenic Variability in Bipolaris sorokiniana Causing Spot Blotch in Wheat (Triticum aestivum, T. durum, T. dicoccum) in India
}

\author{
P.K. Chauhan ${ }^{1}$, D.P. Singh ${ }^{2 *}$ and S.S. Karwasra ${ }^{1}$ \\ ${ }^{1}$ Department of Plant Pathology, CCS HAU, Hisar-125001, Haryana, India \\ ${ }^{2}$ ICAR- Indian Institute of Wheat and Barley Research, Karnal 132001, Haryana, India \\ *Corresponding author
}

\section{A B S T R A C T}

\begin{tabular}{l} 
K e y w o r d s \\
Morphological, \\
Pathogenic, \\
variability, Bipolaris \\
sorokiniana, Spot \\
blotch, Wheat, \\
Triticum aestivum, $T$. \\
durum, T. dicoccum, \\
India. \\
\hline Article Info \\
$\begin{array}{l}\text { Accepted: } \\
\text { 26 September } 2017 \\
\text { Available Online: } \\
\text { 10 November } 2017\end{array}$ \\
\hline
\end{tabular}

\section{Introduction}

The spot blotch caused by Bipolaris sorokiniana (Sacc.) Shoemaker in wheat and Triticale is a major disease problem in warmer and humid regions of India, Bangladesh and other South Asian countries. It causes losses up to $50 \%$ in grain yield and deteriorates seed quality. The host resistance is most effective and easily adopted way to manage the losses caused by this disease in grain and seed crop besides use of fungicides as pre sowing seed treatment and foliar sprays. To achieve durable spot blotch resistance in wheat it is important to identify morphological and pathological variability in
Bipolaris sorokiniana (Sacc.) Shoemaker. Pascual and Raymundo (1995) collected the different isolates of $B$. sorokiniana from different wheat growing locations. Cultural variation was exhibited by 20 isolates when grown of PDA (potato dextrose agar), wheat extract agar and $\mathrm{V}-8$ juice agar medium. A distinct difference in colony morphology was observed among 112, 16 and 118 isolates on PDA. In commercial variety, Trgo-3, isolates differs in virulence as manifested in the components like incubation period, lesion number per 3 sq. cm leaf area and lesion size. Variability in cultural characteristics was 
observed in morphology and growth rate. However, there was no relationship between morphological variability and virulence among 10 isolates (Oliveira et al., 1998). Ahmed et al., (1997) from Bangladesh reported the divergence level among the 27 isolates into 4 clusters. Higher inter-cluster distance was observed between I and IV and the lowest between II and III. Mitra (1931) described the variations in the growth features of two strains of $B$. sorokiniana obtained from wheat and barley on four types of media. Wheat strain always showed the greater development of aerial mycelium.

The mycelia colour of barley strain was deep neutral gray whereas, different shades of gray colour were observed in case of wheat strains on different media. Moderate donation was found in wheat strain and less in barley strain. Binary and Govindu (1975) observed that, ear head isolates had shown significantly faster growth than the leaf neck isolates indicating the presence of cultural variations.

Cultural variability has been reported in the isolates on Czapek's medium. It formed five types of colonies, varying in mycelial colour from greenish-gray at $\mathrm{pH} 4$ to olive-gray at pH 8 (Ermekova and Orynbaev, 1982).

Radial mycelial growth of 83 isolates collected from 11 major wheat-growing areas in Bangladesh varied from 29 to $78 \mathrm{~mm}$ (Hossain and Azad, 1992). Ahmed et al., (1997) observed the variations in colour of isolates in 27 isolates from ash brown, olive green, light green or dark green in colour with regular or wavy margin, fluffy, spread or velvet texture and with or without sectors. Valim et al., (1997) studied the variations in the cultural characters viz. growth rate, colour, presence of sectors, reverse of the sample plate and texture among 10 wheat isolates of $B$. sorokiniana obtained from four wheat growing regions in Brazil.
Christensen (1925) reported 37 biologic forms of Bipolaris sorokiniana from wheat and barley. Mitra in 1931 studied conidial size of wheat and barley strains of $B$. sorokiniana ranged from 16.5 to $102.5 \mu \mathrm{m}$ in length and 13.0 to $26.5 \mu \mathrm{m}$ in breadth, the average being $75.0 \times 21.5 \mu \mathrm{m}$. The septum was $0-10$ with an average of 6.5. The spores were yellow brown to dark olivaceous often with a bluish green tinge. Wood (1962) tested 17 isolates of $B$. sorokiniana obtained from wheat culm, leaves and roots and showed that isolates were differ strikingly in their parasitic capabilities, irrespective of the host or the geographical origin.

Some isolates were extremely virulent, some moderately and others were only weakly pathogenic on barley, oats and wheat. Five isolates of B. sorokiniana from wheat HS-1, HS-2, HS-3, HS-4 and HS-5 collected respectively from Pusa (Bihar), Kanpur and Mahewa (Uttar Pradesh) and Powerkheda (MP) were found most virulent and the isolates HS-1 and HS-5 to some of the wheat cultivars were very marked indicating the existence of fairly distinct physiological races of $B$. sorokiniana within the country (Misra, 1973). The leaf isolates were more virulent than the other isolates in causing more damage to wheat plants.

The leaf and neck isolates and earhead isolates grouped into virulent and less virulent forms respectively. The significant variation of the earhead isolates from the leaf and neck isolates shows the occurrence of physiologic forms of B. sorokiniana in Karnataka (Bidari and Govindu, 1976, 1977). The isolates from Dholi (Bihar) and Bhubaneshwar (Orissa) differed in their pathogenic behaviour on eight wheat varieties. The Dholi isolate was more virulent than the Bhubneshwar one (Misra et al., 1981). Studies by Hossain and Azad (1992) revealed that the peak of sporulation on the host between the period of 
23 and 36 days, after inoculation depending on the cultivars and race of pathogen. However, in most of the cases, it reached after 29 day of inoculation. Ahmed et al., (1997) recorded the number of cells per conidia varied from 3-10 and length and width of conidia varied from 35 to $370 \mu \mathrm{m}$ and 15 to $65 \mu \mathrm{m}$.

Based on a preliminary set of differential cultivars, a total of 32 races in 5 states were reported from Brazil. They appeared very different in adult plants in relation to lesion size and spore production (Mehta, 1981b)). However, the isolates proved to be variable and even lost their pathogenicity over time (Mehta, 1985). Hetzler et al., (1991) confirmed the higher variability of $B$. sorokiniana isolates and identified 15 pathotypes according to their resistance reactions in a differential set. Pathogenic variability of 9 isolates was studied on 24 wheat genotypes using "detached leaf culture" test and reported significant differences in incubation period (IP), lesion length (LL), sporulation (SP) and the isolates were categorized as highly aggressive, aggressive, moderately aggressive and least aggressive. The isolate PHS-3 was found highly aggressive followed by PHS-2, PHS-4 and PHS-5; PHS-6, PHS-8, PHS-9 and PHS-7 and the isolate PHS-1 was least aggressive (Akram and Singh, 2001). The present study was undertaken to detect the variability in $B$. sorokiniana present in all six agro climatic zones of India.

\section{Materials and Methods}

\section{Collection of Samples}

A total of 560 blighted leaf samples of wheat were collected from all over the India and cultures were broadly grouped in to 13 from BS 1-BS 13 and were representing Karnal, Hisar, Ludhiana and Pantnagar (North
Western Plains Zone); Coochbehar, Faizabad and Samastipur (North-Eastern Plains Zone); Vijapur and Pune (Central Zone), Dharwad (Peninsular zone) and Almora (Northern Hills Zone). The blighted leaf samples were collected from more than 350 wheat cultivars and genotypes grown under natural infection conditions from 2000-2005 (Table 1).

\section{Isolation of pathogens}

The isolation of pathogens associated with blighted samples was done on potato dextrose agar (PDA) medium. The pathogen was grown on PDA medium. The composition of PDA was as:

Peeled potato - 200g

Dextrose sugar - 20g

Agar-agar - 20g

Water - added to make total volume upto1000ml.

The blighted spots were cut into 4-5 $\mathrm{mm}$ length pieces along with some healthy green tissue and washed with fresh tap water 2-3 times. These were surface sterilized with $0.1 \%$ solution of $\mathrm{HgCl}_{2}$ (Mercuric chloride) for 30-45 seconds to remove contamination followed by 4-5 washing in sterilized water. The bits were later dried using sterilized blotters and plated on the PDA on sterilized plastic Petri dishes (90 mm diameter) @ 5 pieces per plate at equal distance. These plates were incubated at $25 \pm 1^{\circ} \mathrm{C}$ in $\mathrm{BOD}$ incubator at $12 \mathrm{~h}$ day and night photoperiod cycle to stimulate sporulation in colonies. The colonies developed fully within 10-12 days after inoculation. Pathogens were identified by observing the colony (Alcorn, 1988) under compound stereo binocular microscope initially and later by making slides of spores and observing under compound microscope. The sub-culturing was done on PDA slants in culture tubes and stored at $4^{0} \mathrm{C}$ in refrigerator. 
Purification (by single spore isolation technique)

Single spore culture was prepared by taking spores from fully-grown colony in sterilized water. The spore suspension was later plated by using L-shaped glass rod, on $1.5 \%$ nutrient-agar in Petri dishes. Single spore was spotted by observing Petri dishes under microscope and transferred to new PDA Petriplates using sterilized needle (Duveiller and Altamirano, 2000).

\section{Maintenance of culture}

The cultures obtained using single spores were transferred to PDA slants and after incubation for 10 days these were stored at $4^{0} \mathrm{C}$ upto 8 weeks in refrigerator after putting $\mathrm{Al}$ foil on cotton plugs. The re-culturing was done as per need.

\section{Cultural characters}

The circles of $5 \mathrm{~mm}$ diameter of full-grown colony of each isolate were placed at the center of Petri plates containing PDA. Three replications per isolates were taken. The incubation was done in B.O.D. incubator at $25 \pm 1^{0} \mathrm{C}$. The Petri plates were observed daily after incubation to record colony characteristics. The colony growth started within $24 \mathrm{~h}$ of inoculation. During initial three days only colony growth characters were recorded whereas, colony color and nature of growth were also recorded afterward. Observations were taken upto seven days and final diametric growth was recorded in each colony.

\section{Morphological characters}

The morphological characters of the fungus were observed under in vitro conditions. The spores of each isolate were collected from the Petri plates. The conidial characters were observed under the compound microscope (Olympus, Olympus Singapore PTE Ltd.) after staining with cotton blue dye.

\section{Sporulation}

Five $\mathrm{ml}$ distilled water with Tween-80 was poured in each Petri plate and shaken well to detach the spores in water. The spore suspension was collected in test tubes. A uniform volume of $100 \mu \mathrm{l}$ of spore suspension of each isolate was taken on glass slide with the help of micropipette. The sporulation per microscopic field was counted under 10x and observations were taken at five microscopic fields.

\section{Colour and septation of spores}

The morphological variations for color of spores and its cytoplasm, septation and shape in conidia and conidiophores were observed under microscope by making slides in cotton blue.

\section{Measurement of size of spores}

The length and breadth of spores and sporophores were measured with the help of micrometer. The values of ocular micrometer were multiplied with the constant value of stage micrometer to find out the size in $\mu \mathrm{m}$ scale. The record was taken on 15 spores and sporophores to get the range of size.

\section{Spore germination}

The spore suspension was prepared from 10 days old colony in sterilized water and 5 drops (20 $\mu 1$ each) were taken on the slide and were put in the moist chamber for $12 \mathrm{~h}$ alternate light and dark period, at $25 \pm 1^{0} \mathrm{C}$.

The slides were observed under compound microscope at 10x. The germinated and total spores per microscopic field were counted 
and the per cent germinated spores were calculated.

\section{Nuclear staining}

The deoxy ribonucleic acid (DNA) intercalating fluorochrome, Ethidium Bromide (2, 7-diamino-9-phenyl phenanthridium bromide) was used for nuclear staining by the following procedure:

Fungal spores were mounted in 0.1 per cent solution of ethidium bromide in ethanol-water $(1: 3, \mathrm{v} / \mathrm{v})$ on a glass slide. After 5 minutes, ethidium bromide was replaced with distilled water gradually by absorbing the stain with blotting paper from one end of the cover slip and simultaneously adding water from the other end.

Observations were taken under fluorescent microscope and brightness of fluorescence was recorded under $\mathrm{G}$ excitation (465-500nm) with the DM 580 dichroic mirror (Singh et al., 2002).

\section{Plant material used}

Four genotypes of bread wheat viz. HPW184, HD2733, GW322 and Sonalika and one of durum wheat PBW34, were used to study the pathogenic variability amongst 13 isolates under polyhouse conditions. Plants were grown in 10 inches high pots having sand, FYM and field soil (1:1:2). The healthy looking seeds were surface sterilized and 10 seeds per pot were sown at equal distance.

Controlled environment was maintained by keeping temperature at $30 \pm 2^{\circ} \mathrm{C}$ and relative humidity ranging from $85-95 \%$ with the help of sensors and use of water mists, fans and hot air blowers. The green canopy over polyhouse top was also used during hot summers. The crop plants were raised using recommended package of practices.

\section{Preparation of mass inocula}

\section{Sorghum grain medium}

Mass inocula of 13 isolates were prepared separately in Erlenmeyer flasks of capacity $50 \mathrm{ml}$ each. The sorghum grains $(500 \mathrm{~g})$ were soaked in water overnight. The imbibed grains thus obtained were put in the flasks@ $20 \mathrm{~g} / 100 \mathrm{ml}$ flask. The flasks were later plugged with cotton and covered with butter paper. The filled grains were autoclaved at 20psi for 20 minutes. After cooling, the grains were shaken by jerking the flask against palm of hand gently to avoid clumping. The autoclaved grains were then inoculated with a disc (10mm diameter) of 10 days old colony of each isolate separately and incubated inside B.O.D. incubator at $25 \pm 1{ }^{0} \mathrm{C}$ for 15 days. Flasks were shaken daily to promote sporulation and prevent mycelium clumps. After 10 days the sorghum seeds were fully covered with dark brown to black fungal spores. Inoculum was prepared in sterilized water by taking 10-15 infected sorghum seeds and shaking well. The spores were thus detached from grains in water. To make homogenous spore suspension 1-2 drops of Tween-80 were also added in spore suspension. The suspension thus obtained was sieved through the sterilized muslin cloth to remove mycelium and grains. The spore concentration was adjusted up to 7500 spores/ $\mathrm{ml}$ by diluting the stock solution by counting the spores with haemocytometer under compound microscope.

\section{On PDA}

The Petri-dishes with PDA were inoculated with actively growing mycelial disc $(4 \mathrm{~mm})$ and incubated at $25 \pm 1^{\circ} \mathrm{C}$ with the light and dark period of $12 \mathrm{~h}$ each using fluorescent tubes inside B.O.D. After 10 days of incubation, the colonies were fully developed. The spores from these were collected by 
spraying the sterilized water droplets with the help of glass hand-atomizer and collecting the decant in an empty flask with the help of funnel. The force exerted by atomizer detached the spores from the conidiophores. About 1-2 drops of Tween-80 surfactant per $100 \mathrm{ml}$ of water were also added to reduce the surface tension of water and avoiding floating of spores.

\section{Pathogenic variability}

Development of spot blotch of wheat was studied under controlled conditions i.e. at $30 \pm 1^{\circ} \mathrm{C}$ and $90-95 \%$ R.H. The experiments were conducted in polyhouses by using a differential set of 5 wheat genotypes viz. Sonalika (S), GW322 (MS), HD-2733 (MR), PBW34 (MR) (d) and HPW184 (R) and thirteen isolates of $B$. sorokiniana (BS-1 to BS-13).

The plants were grown under controlled conditions i.e. at $30 \pm 1^{\circ} \mathrm{C}$ and $90-95 \%$ R.H. Five plants per pot were kept for conducting the tests of pathogenic variability. To avoid mixture of isolates, each row of pots was arranged at the distance of $30 \mathrm{~cm}$ (Plate-1b).

\section{Spraying of inoculums}

The spore suspension of each isolate 7500 spore/ml was taken from 15 days old culture and inoculated on 25- 30 days old seedlings at 3-4 leaf stage. The inocula were sprayed with the help of glass atomizer separately in case of each isolate on a set of differential.

The spraying of inocula was done in isolation to avoid drift. A check was kept without spray. The inoculated plants were allowed to dry the droplets on leaves and later kept in polyhouse having humidifiers for $12 \mathrm{~h}$, to provide enough moisture on leaves to enhance infection. These were later incubated for 10 days.

\section{Symptom development}

Initially water soaked spots developed within 2 days. These later turn into yellowing and necrotic area developed on the inoculated leaves. The incubation period of thirteen isolates was recorded in days after inoculation. The observations were taken until the symptoms were appeared on all the plants.

\section{Seedling infection responses (IRs)}

Four grades i.e., S-susceptible, MSmoderately susceptible, MR-moderately resistant and R-resistant grade were given on the basis of the degree of yellow halo around the necrotic spot and size of necrotic spot. Rno yellow halo, MR- small tinge of yellow around necrotic spot, MS- necrotic area surrounded by thin yellow boundary and Sthe yellow halo extended around the necrotic spot and runs parallel to the veins of leaf (Fig. 1). Observations were taken visually in 4 grades.

\section{Number of lesions}

Numbers of lesions were recorded on flag -2 leaves on differential set at 10 days after inoculation (DAI). Visual counting of number of lesions was done for all genotypes of differential set.

\section{Necrotic area}

The length and width of necrotic area after ten days of inoculation was recorded in $\mathrm{mm}$ by using transparent measuring scale. The area was calculated for each necrotic spot by multiplying length and width. Five biggest spots were measured in case of each isolate.

\section{Terminal disease severity}

The terminal disease severity was measured in double-digit figure using 0-9 scales. The 
first digit of scale indicated the per cent area blighted on flag leaf and the second digit represented the per cent leaf area blighted on flag -1 leaf.

\section{Statistical analysis}

The laboratory and Pot experiments were conducted in completely randomized design and the analysis of variance was done as per standard method given by Panse and Sukhatme (1967).

\section{Results and Discussion}

\section{Morphological variability}

\section{Colony growth behaviour}

The differences in the colony growth were observed amongst test isolates (Fig. 2). The mean diametric growth of colonies of different isolates ranged from 16.7 - $40.6 \mathrm{~mm}$ (Table 2). The maximum growth i.e. $40.6 \mathrm{~mm}$ was in the isolate BS-11 while minimum of $16.7 \mathrm{~mm}$ was in isolate BS-5. The Figure 2 clearly shows the isolate BS-11 took lead in growth from beginning till last day of observation and it was significantly superior.

\section{Cultural characters}

The data on the cultural characters of spore and sporophores of $B$. sorokiniana are presented in Table 3. Two types of conidial colours i.e. light brown and dark brown was observed. The light brown colour was observed in 5 isolates (BS-1, BS-4, BS-5, BS11 and BS-12) whereas other isolates displayed dark brown colour (Fig. 2). The sporophores showed more variations in terms of colour viz. light brown, dark brown, brown to dark brown, grayish brown and dark olivaceous. The sporophores of isolate BS-3 reflected the dark olivaceous color whereas BS-11 was of grayish brown color. Likewise, one isolate i.e. BS-2 reflected brown to dark brown shade. On the other hand, dark brown color of sporophores was recorded in isolates BS-1, BS-4, BS-8 and BS-12, while the remaining isolates had the light brown colour.

\section{Septation of spores and sporophores}

The septa in spores ranged from 2-12 (Table 4). Maximum 12 septa were recorded in isolate BS-5 while the minimum 2 in isolates, BS-8, BS-10, BS-11 and BS-12.

The range of septa in sporophores of different isolates varied from 2-8. Minimum 2 septa were observed in isolates, BS-4, BS-5 and BS-6 whereas, maximum 8 septa were recorded in isolates BS-2 and BS-8.

\section{Cytoplasm colour}

The range of colour of cytoplasm was witnessed in spores of different isolates of $B$. sorokiniana. The colour was light blue, blue, brown and greenish blue in the cytoplasm of spores, after staining. It is clear from Table 3 that, only one isolate i.e. BS-2 had the blue color of cytoplasm. Two isolates, BS-1 and BS-4 had the brown color while; isolate BS-3 and BS-10 had light blue color. The cytoplasm of rest of the isolates reflected greenish blue color.

\section{Shape of spores}

Variation in the shape of spores was observed under microscope. The shape of spores were oblong in case of BS-3 and BS-7, slightly curved in BS-4, 9 and BS-13 while; elliptical in isolates BS-1, BS-2, BS-5, BS-6, BS-8, BS-10, BS- 11 and BS-12 (Table 3, Fig. 3).

\section{Sporulation}

A wide range of mean spores i.e. 3.0-88.2 per microscopic field of sporulation was observed 
in different isolates of $B$. sorokiniana (Table 4). The data clearly showed the minimum sporulation i.e. 3.0 was in case of BS-5 while the maximum i.e. 88.2 spores/ microscopic field in isolate BS-13.

\section{Size of spores}

The length and width of spores of different isolates was recorded under microscope, using ocular micrometer. The length of spores ranged from 57.0-85.0 $\mu \mathrm{m}$ while; width from $16.5-24.5 \mu \mathrm{m}$.

The maximum spore length i.e. $85.0 \mu \mathrm{m}$, was observed in isolate BS-8 while the minimum $(57.0 \mu \mathrm{m})$ in isolate BS-2 (Table 5). Likewise, maximum width i.e. $24.5 \mu \mathrm{m}$ was observed in

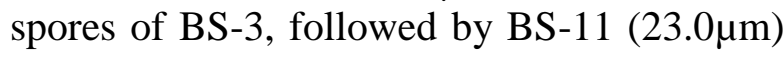
whereas, minimum $(16.5 \mu \mathrm{m})$ in isolate $\mathrm{BS}-1$ (Fig. 3).

\section{Size of sporophores}

The average sporophores length ranged from 69.6-197.0 $\mu \mathrm{m}$. Minimum length $(69.6 \mu \mathrm{m})$ of was exhibited by isolate BS-3 while maximum i.e. $197.0 \mu \mathrm{m}$ in $\mathrm{BS}-8$ (Table 6).

All isolates were significantly different except two, BS-10 and BS-11 in terms of length of sporophores. The sporophores width was ranged from $6.0-10.5 \mu \mathrm{m}$. The maximum width i.e. $10.5 \mu \mathrm{m}$ was observed in isolate BS2 while; the minimum $(6.0 \mu \mathrm{m})$ was recorded in BS-13.

\section{Germination of spores}

The spore germination in 13 isolates ranged from 46.7-95.7 per cent (Table 7). The maximum germination i.e. $96.7 \%$ was observed in isolate BS-2. Most of the isolates showed the significantly different spore germination (\%) and isolate BS-1 had the lowest germination i.e. $46.7 \%$ (Fig. 5).

\section{Fluorescent staining of nuclei}

Conidial cells in all the 13 isolates of $B$. sorokiniana were multinucleate and had shown the great variability (Fig. 4). The number of nuclei present per cell of spore were counted under fluorescent microscope filter and after staining the spore with Ethidium Bromide (2,7-diamino-9-phenyl phenanthridium bromide).

\section{Pathological variability}

\section{Incubation period}

Differences were observed in terms of incubation period. Incubation period for initiation of first symptoms of disease appearance ranged from 5-6 days in susceptible genotype Sonalika (S). Amongst isolates, BS-2, BS-3, BS-8 and BS-9 were quite fast in developing symptoms i.e. in 5 days on Sonalika (Table 9). In case of GW322 (MS), the disease development took place from 5-8 days. Minimum incubation period of 5 days was found in isolate BS-12, whereas, BS-5 took the maximum period of 8 days. Likewise, in moderately resistant (MR) genotype (HD2733) and PBW34 (d) the incubation period ranged from 6 to 7 days. Minimum incubation period was observed in 3 isolates i.e. BS-2, BS-12 and BS-13. Isolate BS-1 and BS-5 had the maximum incubation period of 7 days, which was significantly higher than other isolates. The isolates BS-1, BS-7, BS-8 and BS-10 were not significantly different than BS-5 in terms of time taken in initiation of symptom. Isolate BS-10 exhibited the maximum period of 7 days and the minimum period of 5 days was recorded in BS-2. In case of resistant genotype HPW 184, isolates BS-4, BS-5 and BS-13 took the maximum period of 8 days for symptom development. The average incubation period of all thirteen isolates on five genotypes ranged from 6 to 7 days. It is 
clear from the Table 9, that, the minimum average incubation period of 6 days was observed in isolates BS-2 and maximum (7 days) in isolate BS-5 (Table 8).

Fig.1 Infection responses (IRs) against different isolates of $B$. sorokiniana on wheat seedling leaves

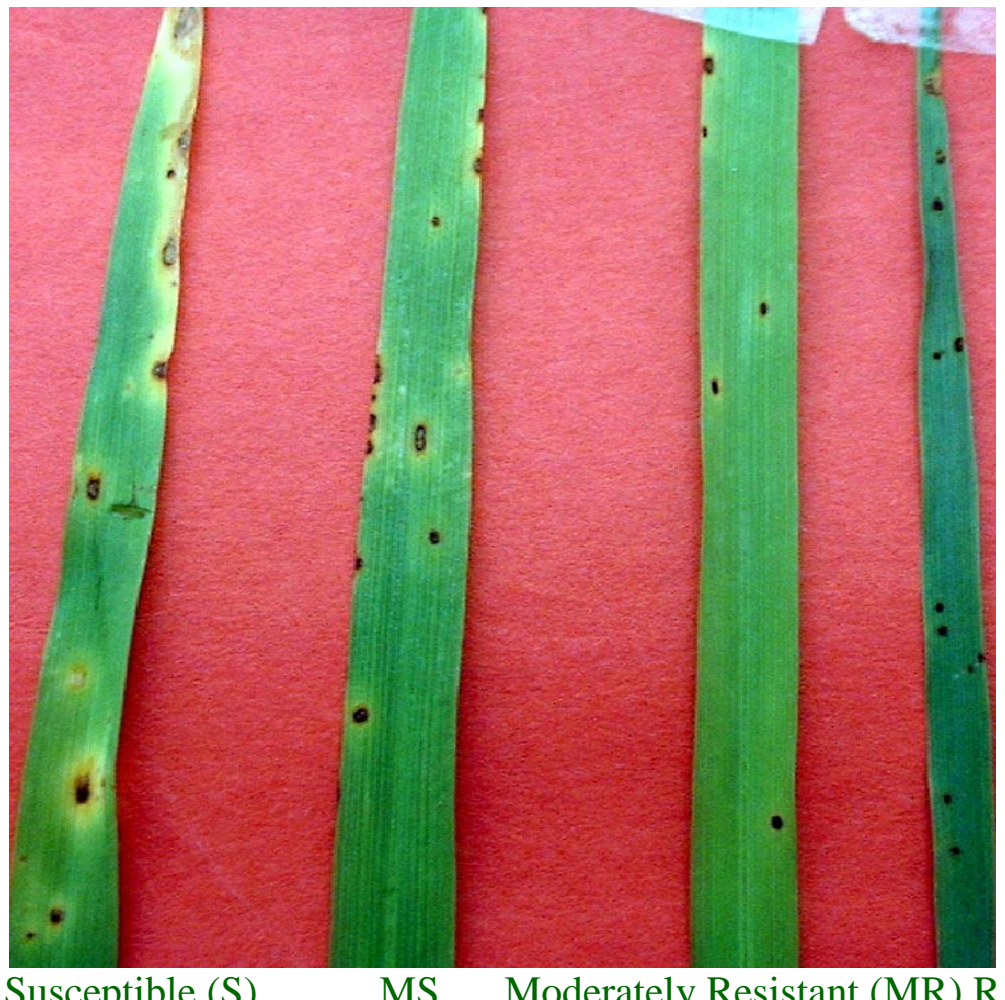

Susceptible (S) MS Moderately Resistant (MR) R

Fig.2 Morphological variations in colonies of B. sorokiniana isolates (BS 1-13)

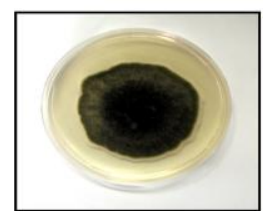

BS-1

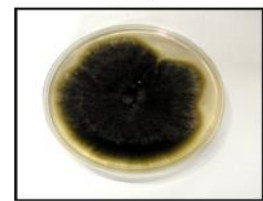

BS-6

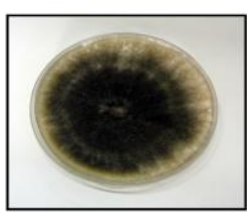

BS-2

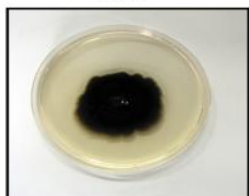

BS-7

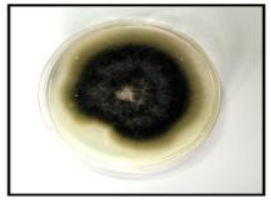

BS-11

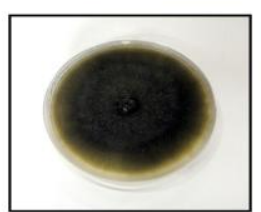

BS-3

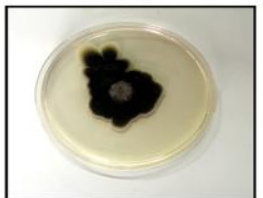

BS-8

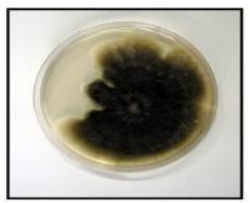

BS-12

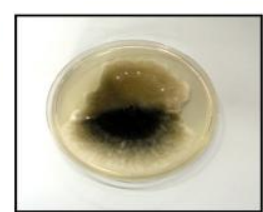

BS-4

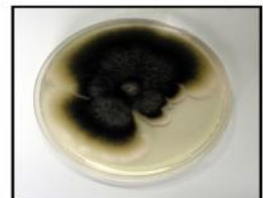

BS-9

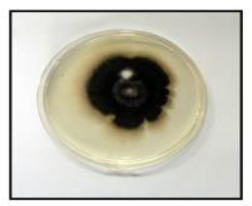

BS-13

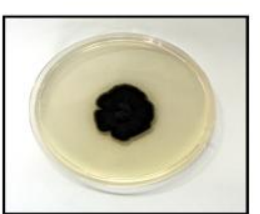

BS-5

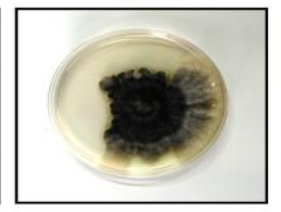

BS-10 
Fig.3 Variability in spore of different isolates of $B$. sorokiniana

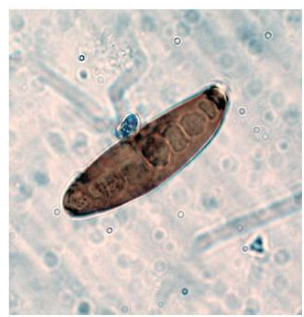

BS-1

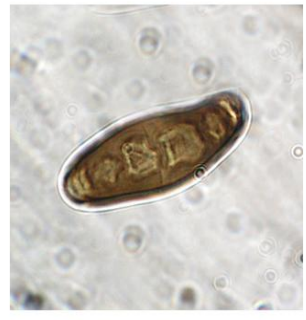

BS-4

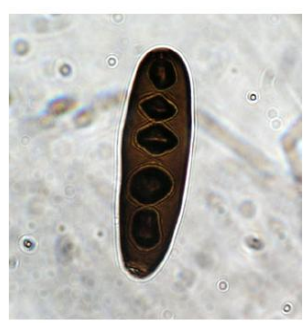

BS-7

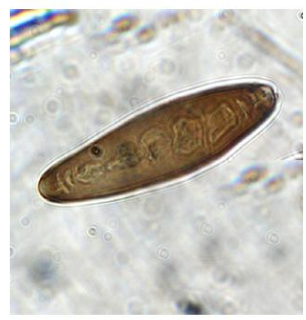

BS-10

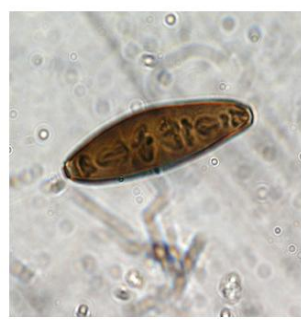

BS-2

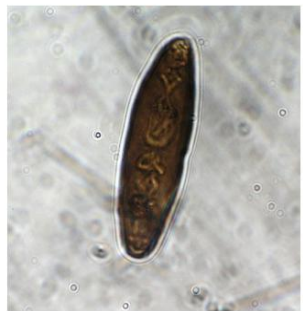

BS-5

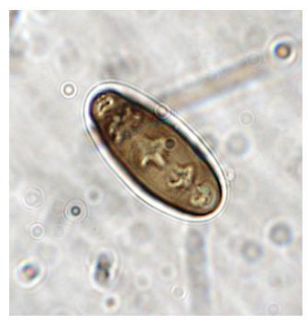

BS-8

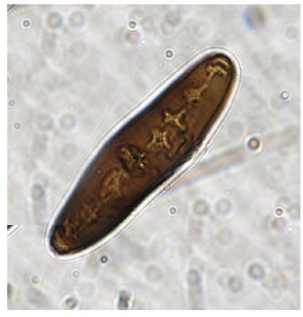

BS-11

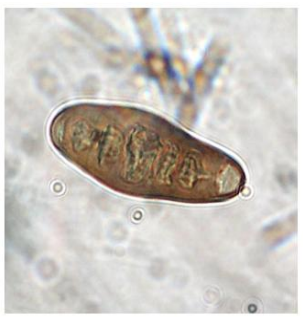

BS-13

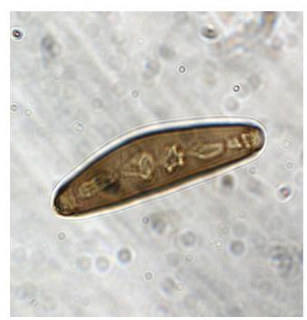

BS-3

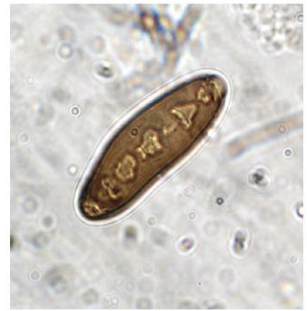

BS-6

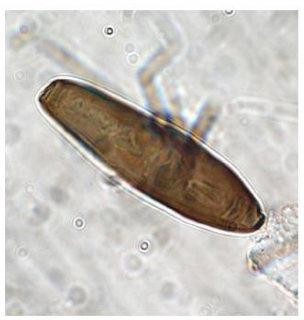

BS-9

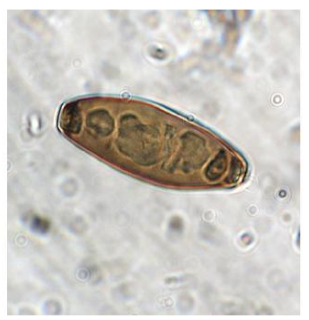

BS-12 
Fig.4 Variability in spore of different isolates of B. sorokiniana seen under flourescence microscope

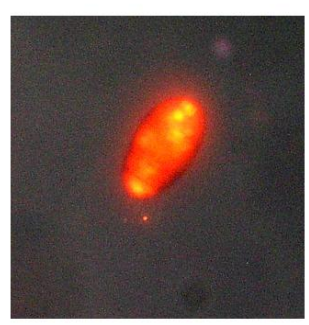

BS-1

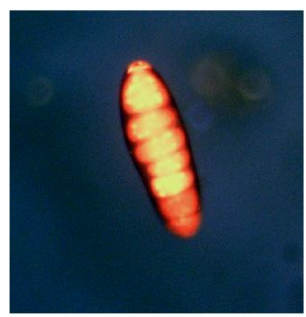

BS-4

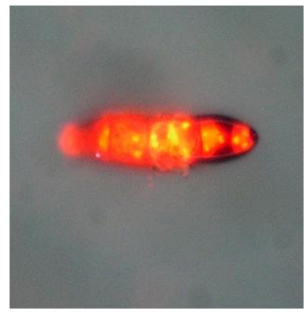

BS-7

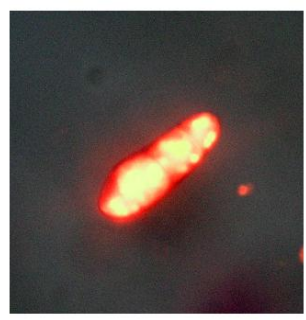

BS-10

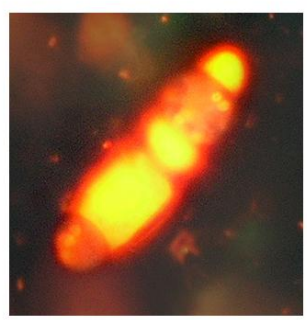

BS-2

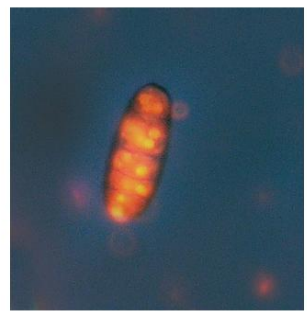

BS-5

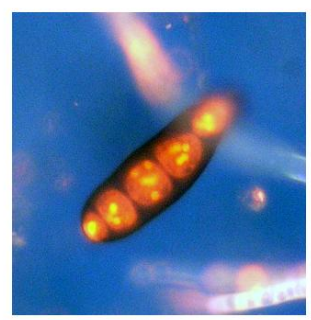

BS-8

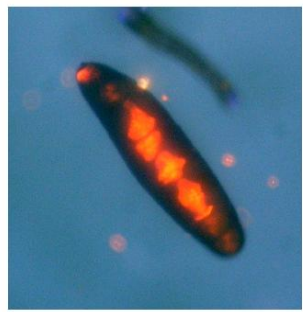

BS-11

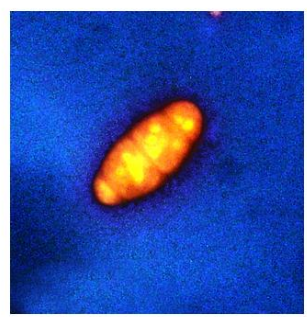

BS-13

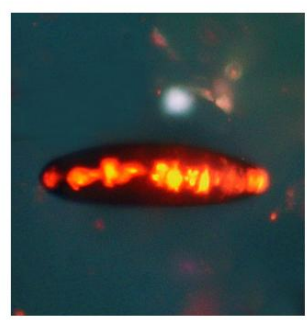

BS-3

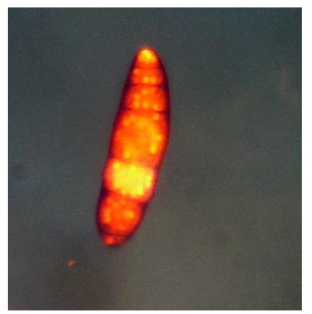

BS-6

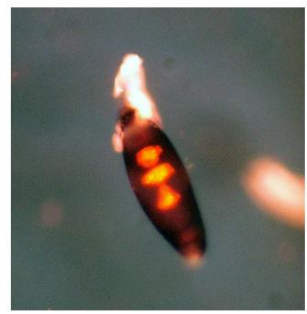

BS-9

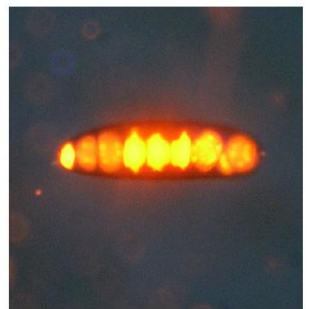

BS-12 
Fig.5 Variations in spore germination in different isolates of B. sorokiniana in distilled water

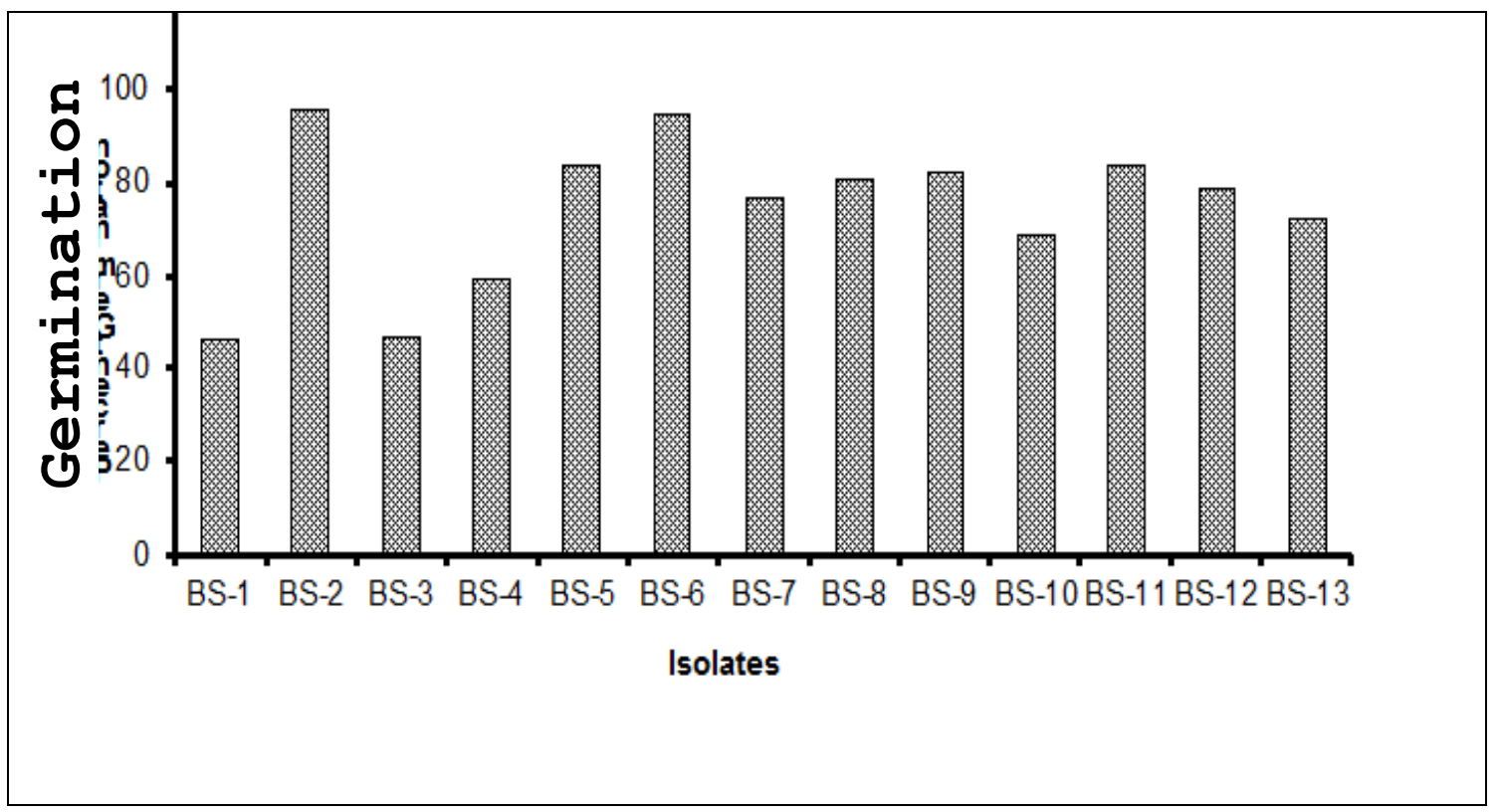

Table.1 Source of different isolates of B. sorokiniana

\begin{tabular}{|c|c|c|c|}
\hline Isolate No. & Genotype* & Origin & Agro-climatic Zone \\
\hline BS-1 & PBW343 & PANTNAGAR & NWPZ \\
\hline BS-2 & Agra Local & KARNAL & NWPZ \\
\hline BS-3 & Raj 4015 & KARNAL & NWPZ \\
\hline BS-4 & MACS & FAIZABAD & NEPZ \\
\hline BS-5 & Raj 4037 & PUNE & CZ \\
\hline BS-6 & Raj 4037 & DHARWAD & PZ \\
\hline BS-7 & Ujjainy Progeny & VIJAPUR & CZ \\
\hline BS-8 & HW 2044 & COOCH BEHAR & NEPZ \\
\hline BS-9 & HD 2329 & HISAR & NWPZ \\
\hline BS-10 & PBW 343 & FAIZABAD & NEPZ \\
\hline BS-11 & PBW 343 & ALMORA & NHZ \\
\hline BS-12 & PBW 542 & LUDHIANA & NWPZ \\
\hline BS-13 & NW 1012 & SAMASTIPUR & NEPZ \\
\hline
\end{tabular}

NWPZ = North-Western Peninsular Zone,

NEPZ= North-Eastern Peninsular Zone,

$\mathrm{CZ}=$ Central Zone, $\mathrm{PZ}=$ Peninsular Zone,

$\mathrm{NHZ}=$ Northern Hill Zone.

$*=$ Blighted leaf samples taken from genotypes. 
Table.2 Growth of different isolates of B. sorokiniana under laboratory conditions

\begin{tabular}{|c|c|c|c|c|c|c|c|c|c|c|c|c|c|c|}
\hline \multirow{2}{*}{$\begin{array}{l}\text { Period after } \\
\text { inoculation }(h)\end{array}$} & \multicolumn{14}{|c|}{ Colony growth (mm) } \\
\hline & BS-1 & BS-2 & BS-3 & BS-4 & BS-5 & BS-6 & BS-7 & BS-8 & BS-9 & BS-10 & BS-11 & BS-12 & BS-13 & Mean \\
\hline 24 & 8.9 & 7.9 & 8.4 & 8.2 & 6.4 & 9.2 & 7.2 & 8.2 & 7.3 & 7.5 & 9.9 & 7.7 & 7.4 & 8.0 \\
\hline 48 & 14.0 & 9.8 & 18.6 & 12.4 & 9.2 & 17.5 & 12.1 & 13.6 & 12.9 & 16.2 & 19.8 & 15.7 & 14.7 & 14.4 \\
\hline 72 & 28.2 & 13.7 & 31.5 & 15.8 & 12.8 & 26.6 & 19.7 & 20.2 & 19.2 & 24.8 & 29.0 & 21.8 & 22.2 & 21.9 \\
\hline 96 & 30.2 & 18.8 & 42.0 & 18.9 & 16.8 & 35.8 & 28.3 & 27.9 & 27.2 & 33.3 & 42.4 & 30.8 & 28.2 & 29.9 \\
\hline 120 & 48.6 & 22.6 & 50.9 & 23.3 & 21.4 & 42.8 & 35.1 & 35.3 & 33.7 & 39.4 & 52.5 & 38.6 & 35.1 & 36.9 \\
\hline 144 & 54.0 & 26.7 & 57.3 & 25.3 & 24.3 & 47.5 & 40.6 & 43.0 & 40.8 & 46.8 & 61.6 & 46.0 & 40.2 & 42.5 \\
\hline 168 & 61.8 & 29.0 & 60.9 & 27.7 & 26.4 & 51.0 & 44.3 & 49.2 & 44.8 & 50.8 & 69.2 & 52.2 & 44.5 & 47.0 \\
\hline Mean & 36.2 & 35.8 & 38.5 & 18.8 & 16.7 & 32.9 & 26.8 & 28.2 & 26.4 & 31.3 & 40.6 & 30.4 & 27.5 & \\
\hline
\end{tabular}

$\mathrm{CD}(\mathrm{P}=0.05)$

$\mathrm{A}($ Isolate $)=3.3, \mathrm{~B}($ Period $)=2.4$

$\mathrm{AB}($ Isolate $\times$ Period $)=8.6$

Table.3 Morphological and cultural variations of Bipolaris sorokiniana isolates

\begin{tabular}{|c|c|c|c|c|c|c|}
\hline \multirow{2}{*}{ Isolate no. } & \multicolumn{2}{|r|}{ Colour } & \multicolumn{2}{|c|}{ No. of Septa } & \multirow{2}{*}{$\begin{array}{c}\text { Cytoplasm } \\
\text { colour }\end{array}$} & \multirow{2}{*}{ Shape of spores } \\
\hline & Spores & Sporophores & Spores & Sporophores & & \\
\hline BS-1 & Light brown & Dark brown & $3-8$ & $3-5$ & Brown & Elliptical \\
\hline BS-2 & Dark brown & Brown to Dark brown & $5-7$ & $3-8$ & Blue & Elliptical \\
\hline BS-3 & Dark brown & Dark olivaceous & $2-9$ & $3-5$ & Light blue & Oblong \\
\hline BS-4 & Light brown & Dark brown & $3-9$ & $2-4$ & Brown & Slightly curved \\
\hline BS-5 & Light brown & Light brown & $3-8$ & $2-4$ & Greenish blue & Elliptical \\
\hline BS-6 & Dark brown & Light brown & $6-12$ & $2-4$ & Greenish blue & Elliptical \\
\hline BS-7 & Dark brown & Light brown & $3-11$ & $3-5$ & Greenish blue & Oblong \\
\hline BS-8 & Dark brown & Dark brown & $2-11$ & $5-8$ & Greenish blue & Elliptical \\
\hline BS-9 & Dark brown & Light brown & $3-9$ & $5-7$ & Greenish blue & Slightly curved \\
\hline BS-10 & Dark brown & Light brown & $2-11$ & $3-6$ & Light Blue & Elliptical \\
\hline BS-11 & Light brown & Grayish brown & $2-11$ & $4-7$ & Greenish blue & Elliptical \\
\hline BS-12 & Light brown & Dark brown & $2-9$ & $3-7$ & Greenish blue & Elliptical \\
\hline BS-13 & Dark brown & Light brown & $6-11$ & $5-7$ & Greenish blue & Slightly curved \\
\hline
\end{tabular}


Table.4 Sporulation in different isolates of B. sorokiniana

\begin{tabular}{|c|c|c|}
\hline S. No. & Isolate & No. of spores/ microscopic field \\
\hline 1 & BS-1 & 13.0 \\
\hline 2 & BS-2 & 23.0 \\
\hline 3 & BS-3 & 42.0 \\
\hline 4 & BS-4 & 15.0 \\
\hline 5 & BS-5 & 3.0 \\
\hline 6 & BS-6 & 21.0 \\
\hline 7 & BS-7 & 24.0 \\
\hline 8 & BS-8 & 21.0 \\
\hline 9 & BS-9 & 55.0 \\
\hline 10 & BS-10 & 32.0 \\
\hline 11 & BS-11 & 37.0 \\
\hline 12 & BS-12 & 54.0 \\
\hline 13 & BS-13 & 88.2 \\
\hline & CD $(\mathbf{P}=\mathbf{0 . 0 5})$ & $\mathbf{1 8 . 0}$ \\
\hline
\end{tabular}

Table.5 Size (length \& width) of spores in different isolates of $B$. sorokiniana

\begin{tabular}{|c|c|c|c|}
\hline S. No. & Isolate & Length $(\boldsymbol{\mu m})$ & Width $(\boldsymbol{\mu m})$ \\
\hline 1 & BS-1 & 64.2 & 16.5 \\
\hline 2 & BS-2 & 57.0 & 19.5 \\
\hline 3 & BS-3 & 58.0 & 24.5 \\
\hline 4 & BS-4 & 66.0 & 21.0 \\
\hline 5 & BS-5 & 59.5 & 20.5 \\
\hline 6 & BS-6 & 81.4 & 21.0 \\
\hline 7 & BS-7 & 68.5 & 18.5 \\
\hline 8 & BS-8 & 85.0 & 17.5 \\
\hline 9 & BS-9 & 66.5 & 21.0 \\
\hline 10 & BS-10 & 59.0 & 22.0 \\
\hline 11 & BS-11 & 73.0 & 23.0 \\
\hline 12 & BS-12 & 71.5 & 20.5 \\
\hline 13 & BS-13 & 58.5 & 18.0 \\
\hline CD (P= 0.05) & & $\mathbf{1 8 . 1}$ & $\mathbf{3 . 0}$ \\
\hline
\end{tabular}

Table.6 Size (length and width) of sporophores in different isolates of B. sorokiniana

\begin{tabular}{|c|c|c|c|}
\hline S. No. & Isolate & Length $(\boldsymbol{\mu m})$ & Width $(\boldsymbol{\mu m})$ \\
\hline 1 & BS-1 & 148.5 & 8.5 \\
\hline 2 & BS-2 & 144.4 & 10.5 \\
\hline 3 & BS-3 & 69.6 & 8.5 \\
\hline 4 & BS-4 & 102.5 & 8.0 \\
\hline 5 & BS-5 & 101.5 & 7.5 \\
\hline 6 & BS-6 & 95.5 & 6.5 \\
\hline 7 & BS-7 & 112.0 & 8.5 \\
\hline 8 & BS-8 & 197.0 & 8.0 \\
\hline 9 & BS-9 & 169.0 & 8.0 \\
\hline 10 & BS-10 & 184.0 & 8.5 \\
\hline 11 & BS-11 & 196.0 & 8.0 \\
\hline 12 & BS-12 & 165.0 & 7.9 \\
\hline 13 & BS-13 & 165.5 & 6.0 \\
\hline CD $(\mathbf{P = 0 . 0 5 )}$ & & $\mathbf{2 7 . 8}$ & $\mathbf{1 . 9}$ \\
\hline
\end{tabular}


Table.7 Germination of spores of different isolates of $B$. sorokiniana

\begin{tabular}{|c|c|c|}
\hline S. No. & Isolate & Germination (\%) \\
\hline 1 & BS-1 & 46.7 \\
\hline 2 & BS-2 & 95.7 \\
\hline 3 & BS-3 & 47.0 \\
\hline 4 & BS-4 & 59.3 \\
\hline 5 & BS-5 & 83.3 \\
\hline 6 & BS-6 & 94.7 \\
\hline 7 & BS-7 & 76.3 \\
\hline 8 & BS-8 & 80.3 \\
\hline 9 & BS-9 & 82.0 \\
\hline 10 & BS-10 & 68.7 \\
\hline 11 & BS-11 & 83.3 \\
\hline 12 & BS-12 & 78.7 \\
\hline 13 & BS-13 & 72.0 \\
\hline CD $(\mathbf{P = 0 . 0 5 )}$ & & $\mathbf{1 9 . 8}$ \\
\hline
\end{tabular}

Table.8 Incubation period (days) in different isolates of B. sorokiniana on different genotypes of wheat

\begin{tabular}{|c|c|c|c|c|c|}
\hline \multirow{2}{*}{ Isolate } & \multicolumn{5}{|c|}{ Incubation period (days) } \\
\cline { 2 - 6 } & Sonalika & GW 322 & HD 2733 & PBW 34 (d) & HPW 184 \\
\hline BS-1 & 5.3 & 5.7 & 7.3 & 5.7 & 5.7 \\
\hline BS-2 & 5.0 & 5.7 & 5.7 & 5.3 & 6.3 \\
\hline BS-3 & 5.0 & 6.3 & 6.3 & 5.7 & 6.7 \\
\hline BS-4 & 6.0 & 6.7 & 5.3 & 7.0 & 8.0 \\
\hline BS-5 & 6.3 & 7.7 & 7.3 & 5.7 & 8.0 \\
\hline BS-6 & 5.3 & 6.7 & 6.3 & 6.0 & 7.7 \\
\hline BS-7 & 5.7 & 6.3 & 5.0 & 5.7 & 7.0 \\
\hline BS-8 & 5.0 & 6.7 & 7.0 & 7.0 & 6.3 \\
\hline BS-9 & 5.0 & 6.3 & 6.0 & 5.7 & 7.0 \\
\hline BS-10 & 5.3 & 6.3 & 6.7 & 7.3 & 7.3 \\
\hline BS-11 & 5.7 & 7.3 & 6.3 & 6.0 & 6.3 \\
\hline BS-12 & 5.7 & 5.0 & 5.7 & 6.3 & 5.7 \\
\hline BS-13 & 6.3 & 6.0 & 5.7 & 5.7 & 8.0 \\
\hline CD (P=0.05) & $\mathbf{1 . 0}$ & $\mathbf{1 . 0}$ & $\mathbf{0 . 8}$ & $\mathbf{1 . 4}$ & $\mathbf{0 . 7}$ \\
\hline
\end{tabular}


Table.9 Infection response of wheat genotypes to isolates of B. sorokiniana

\begin{tabular}{|c|c|c|c|c|c|c|c|c|c|c|c|c|c|c|}
\hline \multirow[b]{2}{*}{ Genotype } & \multicolumn{14}{|c|}{ Infection response (IR) } \\
\hline & BS-1 & BS-2 & BS-3 & BS-4 & BS-5 & BS-6 & BS-7 & BS-8 & BS-9 & $\begin{array}{c}\text { BS- } \\
10\end{array}$ & $\begin{array}{c}\text { BS- } \\
11\end{array}$ & $\begin{array}{c}\text { BS- } \\
12\end{array}$ & $\begin{array}{c}\text { BS- } \\
13\end{array}$ & *Check \\
\hline GW 322 & $S$ & $\mathrm{R}$ & MS & MS & MS & $S$ & MS & MS & MR & $\mathrm{R}$ & MS & MS & $\mathrm{R}$ & NIL \\
\hline HD 2733 & $\mathrm{R}$ & MS & $\mathrm{S}$ & MR & MS & $\mathrm{S}$ & MR & S & S & S & MS & MR & $\mathrm{R}$ & NIL \\
\hline HPW 184 & $\mathrm{R}$ & $\mathrm{R}$ & $\mathrm{R}$ & $S$ & $\mathrm{R}$ & $\mathrm{R}$ & MR & $\mathrm{R}$ & $\mathrm{R}$ & $\mathrm{R}$ & MR & $\mathrm{R}$ & $\mathrm{R}$ & NIL \\
\hline
\end{tabular}

$\mathrm{S}=$ Susceptible, $\mathrm{MS}=$ Moderately Susceptible, MR= Moderately Resistant, $\mathrm{R}=$ Resistant

$*=$ Un-inoculated

Table.10 Development of necrotic lesions on wheat genotypes inoculated with different isolates of Bipolaris sorokiniana

\begin{tabular}{|c|c|c|c|c|c|c|c|c|c|c|c|c|c|c|}
\hline Genotypes & \multicolumn{14}{|c|}{ Necrotic lesion size $\left(\mathrm{mm}^{2}\right)$} \\
\hline Sonalika & 4.1 & 8.5 & 5.2 & 9.3 & 1.0 & 7.4 & 3.6 & 4.4 & 1.1 & 3.3 & 3.8 & 3.1 & 5.1 & 4.6 \\
\hline GW 322 & 1.6 & 1.8 & 0.7 & 1.6 & 3.3 & 0.8 & 1.4 & 0.5 & 1.8 & 1.3 & 0.5 & 0.4 & 0.6 & 1.3 \\
\hline HD 2733 & 0.7 & 2.4 & 0.4 & 1.1 & 0.8 & 0.7 & 0.5 & 0.7 & 0.4 & 1.5 & 1.0 & 0.4 & 1.8 & 1.0 \\
\hline PBW 34 (d) & 2.7 & 4.4 & 2.5 & 5.2 & 1.5 & 0.6 & 5.6 & 4.2 & 0.5 & 0.4 & 1.6 & 1.5 & 2.0 & 2.5 \\
\hline Mean & 2.1 & 3.9 & 1.9 & 3.9 & 1.7 & 2.2 & 2.3 & 2.0 & 0.9 & 1.7 & 1.5 & 1.3 & 2.6 & \\
\hline
\end{tabular}

$\mathrm{CD}(\mathrm{P}=0.05)$

$\mathrm{A}($ Isolate $)=0.2$

$\mathrm{B}($ Variety $)=0.7$

$\mathrm{AB}($ Isolate $\times$ Variety $)=1.4$ 
Table.11 Number of lesions on flag-2 leaf of wheat genotypes with different isolates of $B$. sorokiniana

\begin{tabular}{|c|c|c|c|c|c|}
\hline \multirow{2}{*}{ Isolate } & \multicolumn{5}{|c|}{ No. of lesions / leaf (Average) } \\
\cline { 2 - 6 } & Sonalika & GW 322 & HD 2733 & PBW 34 (d) & HPW 184 \\
\hline BS-1 & 7.2 & 4.2 & 3.2 & 1.2 & 0.8 \\
\hline BS-2 & 9.0 & 5.0 & 5.6 & 2.8 & 2.6 \\
\hline BS-3 & 4.2 & 3.2 & 3.4 & 2.2 & 1.4 \\
\hline BS-4 & 4.8 & 2.8 & 1.8 & 1.8 & 1.2 \\
\hline BS-5 & 5.2 & 3.6 & 3.0 & 1.4 & 1.4 \\
\hline BS-6 & 4.2 & 3.0 & 1.6 & 1.6 & 1.4 \\
\hline BS-7 & 4.4 & 2.8 & 1.8 & 2.4 & 1.8 \\
\hline BS-8 & 6.0 & 2.6 & 2.6 & 1.4 & 1.8 \\
\hline BS-9 & 6.8 & 4.4 & 3.2 & 3.2 & 2.4 \\
\hline BS-10 & 4.8 & 1.4 & 4.0 & 3.4 & 1.4 \\
\hline BS-11 & 4.0 & 2.6 & 1.8 & 2.6 & 1.2 \\
\hline BS-12 & 4.0 & 2.6 & 3.0 & 1.2 & 0.8 \\
\hline BS-13 & 4.2 & 3.8 & 2.8 & 1.2 & 1.6 \\
\hline CD (P=0.05) & $\mathbf{2 . 8}$ & $\mathbf{2 . 3}$ & $\mathbf{1 . 8}$ & $\mathbf{1 . 3}$ & $\mathbf{0 . 9}$ \\
\hline
\end{tabular}

Table.12 Terminal disease severity (double digit) on different wheat genotypes with 13 isolates of $B$. sorokiniana

\begin{tabular}{|c|c|c|c|c|c|}
\hline \multirow{2}{*}{ Isolates } & \multicolumn{5}{|c|}{ Terminal disease severity (0-9 scale on F \& F -1 leaf) } \\
\cline { 2 - 6 } & Sonalika & GW 322 & HD 2733 & PBW 34 (d) & HPW 184 \\
\hline BS-1 & 57 & 24 & 23 & 03 & 02 \\
\hline BS-2 & 68 & 35 & 26 & 23 & 14 \\
\hline BS-3 & 37 & 24 & 13 & 01 & 01 \\
\hline BS-4 & 47 & 23 & 12 & 02 & 12 \\
\hline BS-5 & 36 & 24 & 23 & 12 & 01 \\
\hline BS-6 & 36 & 23 & 04 & 12 & 12 \\
\hline BS-7 & 36 & 12 & 05 & 23 & 13 \\
\hline BS-8 & 46 & 23 & 14 & 01 & 12 \\
\hline BS-9 & 57 & 23 & 13 & 24 & 12 \\
\hline BS-10 & 35 & 12 & 23 & 23 & 12 \\
\hline BS-11 & 35 & 12 & 04 & 12 & 13 \\
\hline BS-12 & 36 & 12 & 12 & 12 & 01 \\
\hline BS-13 & 25 & 24 & 12 & 01 & 13 \\
\hline
\end{tabular}

\section{Infection response (IR) at seedling stage}

Amongst isolates maximum pathogenic virulence was observed in isolate BS-6, showing the maximum frequency of susceptible type (S) IRs on 3 genotypes i.e.
Sonalika, GW322 and HD2733. The isolate BS-13 was the least virulent and all the genotype showed $R$ type of IRs except Sonalika which showed the $\mathrm{S}$ type IR. Isolate BS-4 was the most virulent on resistant genotype HPW 184, which showed S type 
IRs, while with the remaining isolates it showed R type IRs (Table 9).

\section{Number of lesions on flag-2 leaf}

The number of necrotic lesions developed per leaf was counted which are presented in Table 10. Maximum number of lesions 9 and 5 were recorded in case of isolate BS-2 in genotypes Sonalika (S) and GW322 (MS), respectively, whereas, isolate BS-10 produced least number of lesions (4 in S type and 1 in MS type). On genotype HD2733 (MR) maximum 6 lesions developed with BS-2 and minimum two lesions with BS-6. In the genotype PBW34 (MR), the maximum number of lesions (3) were observed in case of isolate BS-10 while; minimum (1) in BS-1, BS-12 and BS-13 isolates (Table 10). In resistant genotype HPW184, the maximum (3) lesions per leaf were observed in case of BS-2 and the least (1 lesion) was found in BS-12 isolate.

The data of Table 11 revealed that, amongst 13 isolates, BS-2 was found most virulent and produced more number of lesions. Isolate BS10 was more virulent on PBW 34 (durum) in terms of higher numbers of lesions per leaf.

\section{Necrotic area development}

In most susceptible genotype Sonalika, the maximum area recorded was $8.5 \mathrm{~mm}^{2}$ in case of isolate BS-2 and the minimum area (1.0 $\mathrm{mm}^{2}$ ) development was observed in case of isolates BS-5. On GW322 (MS) isolate BS-5 was more virulent with necrotic area of $3.3 \mathrm{~mm}^{2}$ and BS-12 was least virulent with 0.4 $\mathrm{mm}^{2}$ necrotic area. The isolate BS-2 developed maximum area $\left(2.4 \mathrm{~mm}^{2}\right)$ on the genotype HD2733 (MR). Whereas, BS-7 has maximum $\left(5.6 \mathrm{~mm}^{2}\right)$ necrotic area on the genotype PBW 34. On resistant genotype HPW 184, the isolate BS-13 produced the maximum sized necrotic spots $\left(3.4 \mathrm{~mm}^{2}\right)$. It has been revealed from Table 10 that, the average necrotic area $\left(3.9 \mathrm{~mm}^{2}\right)$ of maximum size developed in isolate BS-2 and BS-4 while, the minimum $\left(0.9 \mathrm{~mm}^{2}\right)$ in isolate BS9.

\section{Terminal disease severity}

The terminal disease severity was measured on flag and flag -1 leaf by taking per cent leaf area infected in 0-9 scales on $\mathrm{F}$ and $\mathrm{F}-1$ leaf. The highest terminal disease severity 68 was in isolate BS-2 on Sonalika (S) and minimum score of 01 was in isolate BS-3, BS-5 and BS12 on the genotype HPW184 (R). On genotype PBW34 (MR), BS-8 and BS-13 scored the minimum (01) disease severity. The data of Table 13 reveals that, the maximum disease severity has been shown by BS-2 over the differential set except PBW34 (durum), where the isolate BS-9 was most virulent with the maximum (24) disease score (Table 12).

The variations in cultural characters reported in case of present studies are in agreement with those in past reported by Pascual and Raymundo (1995) where, cultural variations were exhibited by 20 isolates grown on three media viz. PDA, wheat extract agar and V-8 juice agar medium. Such morphological variations were also reported in Brazil by Oliveira et al., (1998).

A distinct difference in colony morphology was observed among 112, 16 and 118 isolates on PDA. In the present studies, the isolate BS-11 was the fastest growing and witnessed maximum diametric growth of colony. In contrary to this, isolate BS-5 was distinctly poor in growth with least diametric growth on the seventh day (Table 2). The studies on morphological variations revealed differences in color of spores and sporophores, cytoplasm colour, shape of spores and number of septa per spore as well as sporophores (Table 3). Mitra (1931) also studied the morphology of 
spores of $H$. sativum and reported $0-10$ septation per spore with average of 6.5 . Spores were yellow brown to dark olivaceous often with a bluish-green tinge. Microscopic studies conducted to measure 13 isolates of $B$. sorokiniana revealed variations amongst isolates and maximum sporulation (88.2) per microscopic field was recorded in BS-13 and the minimum (3.2) per microscopic field in BS-5. These results are in conformation with earlier work done by Misra and Singh (1972) and Bidari and Govindu (1976), who reported marked differences in sporulation of the pathogen.

The size of spore and sporophores was measured microscopically. The length of spores ranged between 57-85 $\mu \mathrm{m}$ amongst isolates. The isolate $\mathrm{BS}-8$ had longest spores and sporophores whereas; the BS-2 had the shortest amongst isolates (Table 5). The average length of sporophores was maximum $(197.0 \mu \mathrm{m})$ (Table 6) of isolate BS-8. The variations in average width of spore and sporophores were also observed.

The width of spores ranged from 16.5-24.5 $\mu \mathrm{m}$ and that of sporophores from $6.0-10.5 \mu \mathrm{m}$ respectively. Mitra (1931) also reported variations in the size of spores of $H$. sativum and found spore length ranging from 16.5$102.5 \mu \mathrm{m}$ and width from 13-26.5 $\mu \mathrm{m}$. Tarr and Kafi (1966) also reported variations in five graminaceous species of Helminthosporium in terms of morphological characters of spores and sporophores.

Studies under in vitro condition revealed that, the percent germination of spores ranged from 46.7-95.7. The maximum conidial germination percent $(95.7 \%)$ was observed in BS-2 whereas, minimum (46.7\%) in BS-1 (Table 7). However, Bidari and Govindu (1975) have reported hundred per cent germination in $H$. sativum. Singh and Kumar used Ethidium bromide for the first time to stain nuclei in several fungi like Rhizoctonia solani, Fusarium oxysporum, Phytophthora infestans, Venturia inaequalis etc. Excellent nuclear staining was obtained in all of the test fungi. They found variations at nuclear level in all the fungi. In the present study the work done on nuclear staining with ethidum bromide also resulted into the high variability at nuclear level (Fig. 4).

A weak correlation between field inoculation and seedling infection was reported in case of leaf blight pathogen of wheat by Duveiller $e t$ al., 1998. Duveiller and Altomirana (2000) reported that pathogenicity of 27 isolates of $B$. sorokiniana, obtained from roots, leaves and grains of spring wheat showed no clear difference between groups of isolates on the basis of lesion density. In present studies, the variation in number of lesions per leaf was observed in case of different isolates. The average lesion number varies from 0.8-9.0 for different isolates of $B$. sorokiniana on a differential set of five genotypes viz., Sonalika, GW 322, HD 2733, PBW 34 and HPW 184 (Table 11).

The necrotic area development on differential set of genotypes after inoculation of various isolates of B. sorokiniana ranged from 0.4$8.5 \mathrm{~mm}^{2}$ on an average (Table 10). The results of necrotic area and other pathological tests viz. incubation period, infection response, number of lesions and terminal disease severity, were found independent to each other. Mehta (1981a) reported that components of partial resistance like conidial production, sporulation period and rate of lesion extension act independently. The rate of lesion extension and fungal lesion size were considered to be the desirable parameter of partial disease resistance.

The fungal disease assessment was done in double digit by using 0-9 scales. A high degree of pathogenic variability was observed 
after scoring the disease, at dough stage. The disease score ranged from 01 to 68 in case of different isolates on a set of differential genotypes (Table 13). Karwasra et al., (1998); Pandey and Tiwari, (1999); and Singh et al., (2000) used the double-digit scale to measure the disease severity at final stage. Harding (1984) isolated spore colour mutants of Cochliobolus sativus from naturally infected subcrown internodes of wheat and barley. A collection of 30 'albino' isolates, including 3 produced experimentally, was characterized for several attributes. On minimal medium the spore mass appeared as either white, tan or gray in colour. There were marked differences in colony morphology on a range of media containing different protein hydrolysates. All mutants produced a toxin which inhibited wheat seed germination.

\section{Acknowledgements}

Thanks to ICAR for supporting the studies in terms of grant of funds vide AP cess fund Project No. 3-7/2001/PP.

\section{References}

Adlakha, K.L.; Wilcoxson, R.D. and Ray Chaudhari, S.P. 1984. Resistance of wheat to leaf spot caused by Bipolaris sorokiniana. Plant Dis., 68: 4,320-321.

Ahmed, A.U., Rahman, M.Z., Bhuiyan, K.A. and Mian, I.H. 1997. Variation in the isolates of Bipolaris sorokiniana from wheat. Bangladesh J. Pl. Path., 13 (12): $29-35$

Akram, M. and Singh, A. 2001. Variability and characterization of host response to Helminthosporium sativum, incitant of spot blotch of wheat. Indian Phytopath., 54: 429-434.

Alcorn, J.L. 1988. The taxonomy of "Helminthosporium" species. Ann. Rev. Phytopathol. 26: 37-56.

Bidari, V.B. and Govindu, H.C. 1975.
Comparative studies on the physiology of leaf, neck and earhead isolates of Helminthosporium sativum Pamm, King and Bakke parasitic on wheat crop in Karnataka. Mysore J. Agric. Sci., 9: 421-426.

Bidari, V.B. and Govindu, H.C. 1976. Effect of media and temperature on germination of conidia of three isolates of Helminthosporium sativum on wheat in Karnataka. Mysore J. Agric. Sci. 10: 615-617.

Christensen, J.J. 1925. Physiologic specialization and mutation in Helminthosporium sativum. Phytopathology, 15: 785-795.

Drechsler, C. 1923. Some graminicolous species of Helminthosporium. J. Agri. Res., 24: 641-739.

Duveiller, E. and Altomirana, I.G. 2000. Pathoginicity of Bipolaris sorokiniana isolates from wheat roots, leaves and grains in Mexico. Pl. Path., 49: 235242.

Ermekova, B.D. and Orynbaev, S.O. 1982. Morphological variability of Helminthosporium sativum Pamm., King and Bakke and Alternaria tenuis Nees in relation to $\mathrm{pH}$ of media. Botanichestie Materialy Gerbariya Institute Botaniki Akademii Nauk Kazakhstoĭ SSR. No. 12: 90-91.

Harding, H. 1984. Spore-colour mutants of Bipolaris sorokiniana. Can. J. Pl. Pathol., 6: 273-279.

McRae, W. 1924. Report of the Imperical Mycologist. Sci. Repts. Imper. Inst. Agr. Res. Pusa, 1922-23, pp.53-60.

Mehta, Y.R. 1981a. Conidial production, sporulation period and extension of lesion of Helminthosporium sativum on flag leaves of wheat. Pesq. Agropec. Bras., 16: 331-336.

Mehta, Y.R. 1981b. Identification of races of Helminthosporium sativum of wheat in Brazil. Pesx. Agropec. Bras., 16: 331- 
336.

Misra, A.P. and Singh, R.A. 1972. Comparative pathogenicity of different species of Helminthosporium on wheat in India. Proc. $59^{\text {th }}$ Indian Sci.Congr. pp 567.

Misra, A.P., Pandey, S.P. and Mishra, A.K. 1981. Pathogenic differences in isolates of Bipolaris sorokiniana shoemakers (Helminthosporium sativum $\mathrm{P}, \mathrm{K}$ and $\mathrm{B}$ ) from wheat, barley and triticales from different geographical regions. (Abstr.) $3^{\text {rd }}$. Int. Symp. Pl. Path. IARI, New Delhi, 131-132.

Mitra, M. 1931. A comparative study of species and strains of Helminthosporium on certain Indian cultivated crops. Trans. Brit. Mycol. Soc. 15: 254-293.

Oliveira, A.M.R., Matsumara, A.T.S., Prestes, A.M. and Vander Sand, S.T. 2002. Intraspecific variability of Bipolaris sorokiniana isolates determined by Random Amplified Polymorphic DNA (RAPD), Gent. Mol. Res., 1 (4): 350358.

Oliveira, A.M.R., Matsumara, A.T.S., Prestes, A.M., Motos, G.S. and Sand, S.T.V. 1998. Morphological variability and pathogenicity in isolates of Bipolaris sorokiniana. Fitopatol. Bras., 23(3): 349-353.

Oliveira, A.M.R., Matsumura, A.T.S., Prestes, A.M., Matos, G.S., Sand, S.T.,Vander, Vander, Sand S.T. 1998. Morphological variability and pathogenicity in isolates of Bipolaris sorokiniana. Fitopatol. Bras., 23: 349-353.

Panse, V.G. and Sukhatme, P.V. 1967. Statistical methods for agricultural workers. ICAR, New Delhi. pp. 381.

Pascual, C.B. and Raymundo, A.D. 1995. Variability of Helminthosporium sativum isolates causing leaf spot in wheat. Philippines Journal of Crop Science (Philippines), Nov. 1991,V. 16
(Supplement no.-1): S38.

Robles, L.H. 1949. The pathogenicity of Helminthosporium on corn. Phytopathology, 39: 1020-1028.

Rohlf, F.J. 1998. NTSYS-pc. Numerical Taxonomy and Multivariate Analysis System. Version 2.01, Setauket, New York.

Ruckstuhl, M. 1998. Population structure and epidemiology of Bipolaris sorokiniana in the rice-wheat cropping pattern on Nepal. In: Helminthosporium Blights of Wheat: Spot Blotch and Tan Spot. Duveiller, E., Dubin, H.J., Reeves, J. and McNab, A. (Eds.), Mexico, D. F.: CIMMYT.

Sambrook, J., Fritsch, E.F., Maniatis, T. 1989. Molecular cloning. A laboratory course manual. Cold Spring Harbour Laboratory Press, New York.

Singh, D.P. and Kumar, P. 2005. Methods for scoring of leaf blight of wheat caused by Bipolaris sorokiniana (Sacc.) Shoem. at adult stage on top two leaves and its validation. In: Integrated Plant Disease Management (Eds. Sharma, R.C. and Sharma, J. N.). Scientific Publishers (India). Jodhpur, pp. 289294.

Singh, D.P., Nagarajan, S., Goel, L.B., Kumar, J., Ram, B., Singh, R.M., Singh, R.V., Singh, A., Tiwari, A.N., Verma, P.C., Bagga, P.S., Maity, S.S., Singh, A.K., Singh, S.P. and Singh, R. 2000. Evaluation of wheat lines for resistance to leaf blight, caused by Bipolaris sorokiniana and Alternaria triticina. Pl. Dis. Res., 15:110-12.

Singh, D.P., Sharma, A.K., Singh, A., Singh, R.V., Tiwari, A.N., Singh, A.K., Singh, R.N., Singh, S.P., Khanna, B.M., Dodan, D.S., Bagga, P.S. and Kalappanavar, T.K. 2002. Losses due to leaf blight in wheat in different agroclimatic zones of India. $\mathrm{Pl}$. Dis. Res., 17: 313-317. 
Singh, U.S. and Kumar, J. 1991. Staining of nuclei in fungi by ethidium bromide, Biotechnic Histochem., 66: 266.

Singh, V., Singh, U.S., Singh, K.P., Singh, M. and Kumar, A. 2002. Genetic diversity of Rhozoctonia solani isolates from rice: differentiation by morphological characteristics, pathogenicity, anastomisis behaviour and RAPD fingerprinting. J. Mycol. Pl. Path., 32 (3): 332-344.

Subrmaniam, C.V. 1983. Hyphomycetes: Taxonomy and Biology. Academic Press Inc. Clondon Ltd., 502 pp.

Tarr, S.A.J. and Kafi, A. 1966. Growth, sporulation and conidial characteristics of five graminicolous species of Helminthosporium. In: Effects of Nutrients. Trans. Brit. Mycol. Soc., 49:327-337.

Valim, L.M., Prestes, A.M., Vander, S.S. Matsumara, A.T.S. and Vander, S.S. 1997. Variation in cultural characteristics, morphology and virulence among isolates of Bipolaris sorokiniana. Fitopatol Bras., 22: 483487.

Wood, L.S. 1962. Relation of variation in Helminthosporium sativum on seedling blight of small grains. Phytopathology, 52: 493-498.

\section{How to cite this article:}

Chauhan, P.K., D.P. Singh and Karwasra, S.S. 2017. Morphological and Pathogenic Variability in Bipolaris sorokiniana Causing Spot Blotch in Wheat (Triticum aestivum, T. durum, T. dicoccum) in India. Int.J.Curr.Microbiol.App.Sci. 6(11): 3499-3520.

doi: https://doi.org/10.20546/ijcmas.2017.611.412 